\title{
Engineering Preparatory Programs: Students' ACADEMIC MOTIVATION
}

\author{
Aharon Gero and Gershon Abraham \\ Department of Education in Technology and Science \\ Technion - Israel Institute of Technology \\ gero@technion.ac.il
}

\begin{abstract}
Engineering preparatory programs (EPPs) offer candidates who have not attained adequate achievements during their secondary education an opportunity to improve their chances to be accepted to undergraduate engineering programs. In light of the importance of academic motivation in EPPs, this study characterized the motivational factors for studying engineering in students attending an EPP in Israel. Forty students took part in the study which utilized quantitative tools. The findings indicate that the students were primarily motivated by interest in studying engineering (intrinsic motivation) and by recognition of their inherent value (identified regulation). However, a comparison of the Relative Autonomy Index to the one of excelling 12th grade students majoring in engineering reveals a significant difference between the two groups. This gap, in favor of the high school students, is characterized by a medium effect size.
\end{abstract}

Keywords: engineering preparatory programs, motivation, self-determination theory.

\section{INTRODUCTION}

Engineering preparatory programs (EPPs) offer candidates who have not attained adequate achievements in their high school studies an opportunity to improve their chances to be accepted to undergraduate engineering programs [1]. On EPPs, which typically last 40 weeks (35 hours per week), students intensively study mathematics, physics and English at a high school level.

Due to the students' weak academic background, the program intensity, and the considerable student dropout rate, motivation plays an important role in EPPs [2]. The relevant literature, however, mainly deals with the academic motivation of high school students involved in engineering activities [3]-[4] and of undergraduate engineering students [5]-[6]. Therefore, the goal of this study was to characterize the motivational factors for studying engineering in students attending an EPP in Israel. Self-determination theory [7], which is one of the leading theories in the field of educational motivation, served as the theoretical framework for this study.

The contribution of the study is twofold. Theoretically, the study may improve the understanding of the factors that drive EPP students to study engineering and the role of motivation in these students. In addition, the study's contribution may be reflected in the implementation of its findings to increase the motivation of students attending EPPs, and, hence, decrease the dropout rate.

\section{SELF-DETERMINATION THEORY}

The term motivation relates to the individual's wish to dedicate time and effort to a particular activity, even when this involves difficulties or failures. Theories of motivation attempt to trace the source of motivation and explain processes that drive the individual to behave as he/she does.

Self-determination theory claims that the individual can be brought to a high degree of perceived autonomy (or autonomous motivation), which allows him/her to attain self-actualization, by supporting his/her three basic needs [7]: the need for autonomy - the need to feel that the individual's behavior is not forced upon him/her; the need for competence - the need to feel that the individual is capable and can attain challenging goals; and the need for relatedness - the individual's need to communicate with others and be part of a group.

According to this theory, the factors driving an individual can be placed along a continuum. The continuum extends between the pole of perceived autonomy and the opposite pole of perceived control [8]. The major motivational factors along this continuum will be described below, with perceived autonomy gradually decreasing. Intrinsic motivation stemming from interest and pleasure that are derived from the activity by the individual is the motivational factor characterized by the highest degree of perceived autonomy. The next factor along this spectrum, identified regulation, has as its source the identification of the activity's importance to the individual's goals or values. Introjected regulation is the next motivational factor, representing the wish to 
receive appreciation from others for performing the activity, or alternatively, the wish to avoid the feelings of guilt attached to a failure to perform it. The factor characterized by the lowest degree of perceived autonomy and positioned on the opposite end of the spectrum is external regulation. This factor reflects the wish to attain material compensation for the activity, or alternatively, the fear of being penalized for failing to perform it.

The Relative Autonomy Index (RAI) is a customarily used instrument permitting the individual's autonomous motivation to be estimated [9]. The index is obtained through a linear combination of the different motivational factors with appropriate weights:

$$
\mathrm{RAI}=3 \mathrm{~S}_{\text {Intrinsic }}+\mathrm{S}_{\text {Identified }}-\mathrm{S}_{\text {Introjected }}-3 \mathrm{~S}_{\text {External }}
$$

In definition (1), $S_{i}$ is the score of motivational factor $i$ as measured by an appropriate research tool. It can be seen that the index assigns higher weight in absolute terms to a particular factor when it is closer to one of the poles of the continuum. Additionally, the motivational factors characterized by relatively high perceived autonomy are assigned positive weight, whereas the ones characterized by relatively high perceived control are assigned negative weight.

It should be noted that self-determination theory has served as the theoretical framework for many studies focusing on the academic motivation of high school students [10]-[11] and university students [12]-[13]. Therefore, it formed the theoretical framework for this study.

\section{RESEARCH GOAL AND METHODOLOGY}

The aim of this study was to characterize the motivational factors for studying engineering in students attending an EPP in Israel.

Forty students took part in the study which utilized quantitative instruments. The participants filled out an anonymous questionnaire in the middle of the program. This five-point Likert-like questionnaire, ranging from "strongly disagree" to "strongly agree", was based on the Self-Regulation Questionnaire - Academic (SRQ-A) scale [9]. The questionnaire included twenty statements reflecting the four major motivational factors defined above. For example, the statement "I am interested in studying engineering because I think it will be interesting" represents intrinsic motivation; the statement "I am interested in studying engineering because this will benefit me in the future" expresses identified regulation; the statement "I am interested in studying engineering because my parents want me to study this subject" reflects introjected regulation; and the statement "I am interested in studying engineering because I have no choice" represents external regulation. The statements were validated by two experts in engineering education and
Cronbach's alphas (0.78-0.86) showed good internal consistency. The quantitative data were statistically analyzed, and the RAI was calculated.

\section{RESULTS AND DISCUSSION}

The findings reveal that the students were primarily motivated by intrinsic motivation $(M=3.98$, where $1 \leq M \leq 5 ; S D=0.65)$ and identified regulation $(M=3.72$; $S D=0.57)$. Introjected regulation was in the third place $(M=2.36 ; S D=0.66)$ and external regulation was the less important factor $(M=2.19 ; S D=0.93)$.

However, a comparison of the RAI $(M=6.73$, where $|M| \leq 16 ; S D=3.84)$ to the one of excelling 12th grade students majoring in engineering $(M=8.53 ; S D=3.49)$ reveals a significant difference $(t(70)=2.05 ; p<0.05)$ between the two groups [14]. This gap, in favor of the latter, is characterized by a medium effect size $(d=0.49)$. In view of self-determination theory, the gap may indicate that the EPP students' needs for autonomy, competence, and relatedness were only partially met during the course of the studies [7].

\section{CONCLUSIONS}

The study described in this paper characterized the motivational factors for studying engineering in students attending an EPP in Israel. The findings indicate that the students were primarily driven by interest in studying engineering (intrinsic motivation) and by recognition of their inherent value (identified regulation). However, the degree of relative autonomy in the EPP students was significantly lower than that measured in outstanding 12 th grade students majoring in engineering.

\section{References}

[1] D. Arendale, "Terms of endearment: Words that define and guide developmental education," Journal of College Reading and Learning, vol. 35, no. 2, pp. 66-82, 2005.

[2] K. Zoabi, "Self-esteem and motivation for learning among minority students: A comparison between students of pre-academic and regular programs," Creative Education, vol. 3, no. 8, pp. 1397-1403, 2012.

[3] A. Gero, "Interdisciplinary program on aviation weapon systems as a means of improving high school students' attitudes towards physics and engineering," International Journal of Engineering Education, vol. 29, no. 4, pp. 1047-1054, 2013.

[4] A. Gero and E. Zach, "High school programme in electro-optics: A case study on interdisciplinary learning and systems thinking," International Journal of Engineering Education, vol. 30, no. 5, pp. 11901199, 2014. 
[5] C. Koh, H. S. Tan, K. C. Tan, L. Fang, F. M. Fong, D. Kan, S. L. Lye, and M. L. Wee, "Investigating the effect of $3 \mathrm{~d}$ simulation-based learning on the motivation and performance of engineering students", Journal of Engineering Education, vol. 99, no. 3, pp. 237-251, 2010.

[6] A. Gero, "Engineering students as science teachers: A case study on students' motivation," International Journal of Engineering Pedagogy, vol. 4, no. 3, pp. 55-59, 2014.

[7] E. L. Deci and R. M. Ryan, "The 'what' and 'why' of goal pursuits: Human needs and the self-determination of behavior," Psychological Inquiry, vol. 11, no. 4, pp. 227-268, 2000.

[8] R. M. Ryan and E. L. Deci, "Self-determination theory and the facilitation of intrinsic motivation, social development, and well-being," American Psychologist, vol. 55, no. 1, pp. 68-78, 2000.

[9] R. M. Ryan and J. P. Connell, "Perceived locus of causality and internalization: Examining reasons for acting in two domains," Journal of Personality and Social Psychology, vol. 57, no. 5, pp. 749-761, 1989.

[10] S. J. Bourgeois and J. E. Boberg, "High-achieving, cognitively disengaged middle level mathematics students: A self-determination theory perspective," Research in Middle Level Education, vol. 39, no. 9, pp. 1-18, 2016.

[11] G. Hagay and A. Baram-Tsabari, "A strategy for incorporating students' interests into the high school science classroom," Journal of Research in Science Teaching, vol. 52, no. 7, pp. 949-978, 2015.

[12] A. Gero, "Improving intrinsic motivation among sophomore electrical engineering students by an introductory project," International Journal of Engineering Pedagogy, vol. 2, no. 4, pp. 13-17, 2012.

[13] M. W. Ohland, D. Giurintano, B. Novoselich, P. Brackin, and S. Sangelkar, "Supporting capstone teams: Lessons from research on motivation," International Journal of Engineering Education, vol. 31, no. 6, pp. 1748-1759, 2015.

[14]A. Gero and O. Danino, "High-school course on engineering design: Enhancement of students' motivation and development of systems thinking skills," International Journal of Engineering Education, vol. 32, no. 1A, pp. 100-110, 2016. 